\title{
La Historia del Arte en España. Devenir, discursos y propuestas
}

\author{
MOLINA, Álvaro (Ed.) \\ Ediciones Polifemo, Madrid, 2016
}

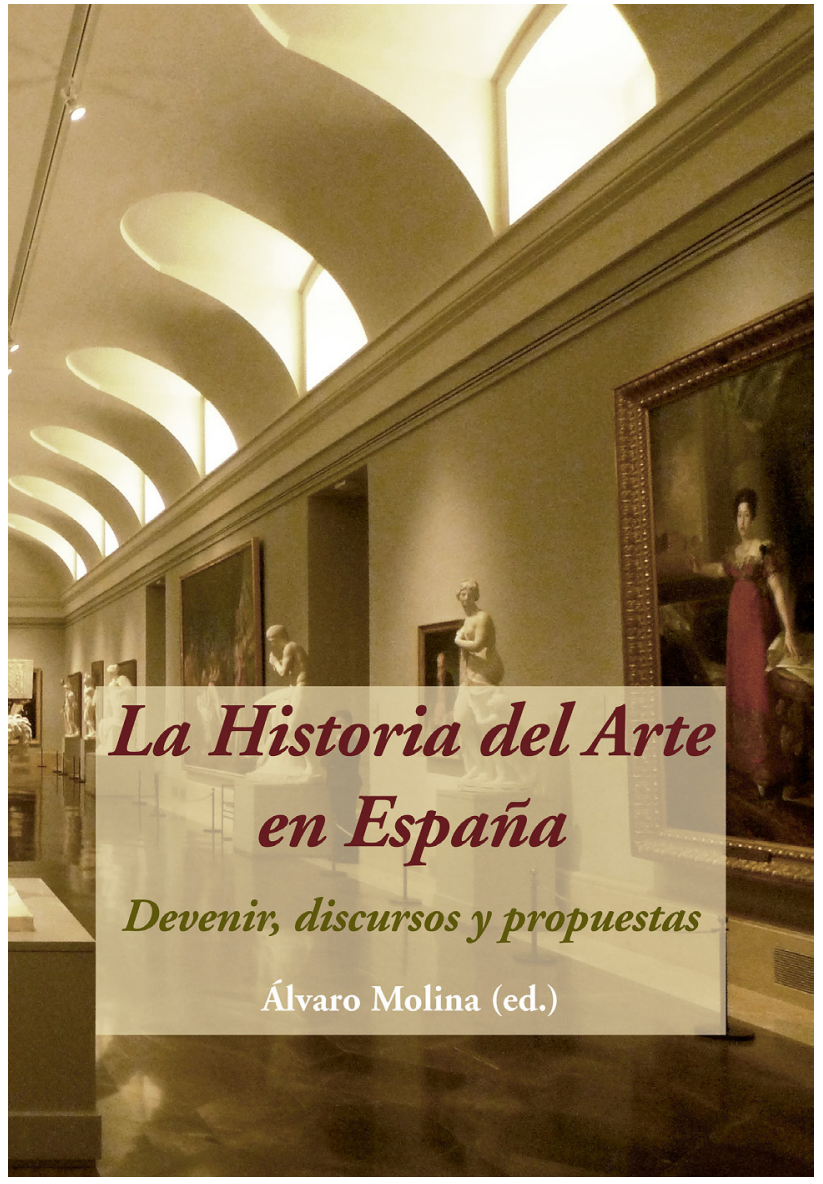

A lo largo de la última década, la preocupación por la historiografía como punto de partida y motor de reflexiones disciplinares ha aumentado exponencialmente entre los historiadores del arte en España, más allá del estudio sobre los años de la dictadura donde ha sido tradicionalmente intensa y frecuente. Diversos proyectos de investigación han puesto el acento sobre esta cuestión, como el desarrollado entre la Universidad de Málaga y el CSIC Análisis estratégico y dinámico de la investigación en Historia del Arte, que analiza las publicaciones y las redes de conocimiento en el seno de la disciplina a partir de 1975, o el dirigido por Wifredo Rincón en el CSIC Imágenes del Nuevo Mundo: el patrimonio artístico Portugués e Iberoamericano a través del legado fotográfico de Diego Angulo al CSIC, que más allá de la catalogación y puesta en valor de este fondo, ha analizado su imbricación en el desarrollo de la disciplina y su papel como generador de un determinado discurso historiográfico.

Sin embargo, este interés no ha corrido en paralelo a un profundo debate sobre las nuevas herramientas metodológicas, ni ha sobrepasado necesariamente las fronteras del ámbito académico, incluso llegando de forma desigual a las aulas universitarias. Este libro, resultado del proyecto de investigación La historia del arte en España: devenir, discursos y propuestas de futuro, propone una reflexión de conjunto sobre todos estos aspectos en torno a la disciplina y en ello radica su originalidad y su enorme valor para la actualidad de la misma.

Como el editor del libro reconoce en su introducción, es prácticamente imposible abordar un tema tan amplio y diverso desde una perspectiva totalizadora, por lo que se ha optado por una publicación coral en la que diez autores comparten una serie de aproximaciones y reflexiones sobre sus campos de estudio específicos. Aunque el énfasis se pone en la construcción del discurso histórico-artístico y su devenir, las preocupaciones sobre el debate metodológico, especialmente las referentes a las nuevas historias del arte y su problemática recepción en España, así como sus posibilidades de encaje en los respectivos campos de estudio, jalonan gran parte de los ensayos.

El objetivo de esta publicación, como se explicita en el propio volumen, no fue presentar una exposición cerrada, sino establecer un diálogo con el lector desde la reflexión personal sobre las preocupaciones en la propia práctica. Este punto de partida hace que este sea un libro enormemente comprometido, honesto y valiente. Comprometido, porque desde un inicio se deja claro que se pretende traspasar las fronteras de la investigación y que el ejercicio de la historia del arte se concibe también desde la enseñanza 
(universitaria y de ciclos medios), desde las prácticas museológicas, desde los proyectos editoriales, en definitiva, plantea el necesario diálogo y compromiso de la disciplina con la sociedad.

El ejercicio profesional de sus autores, vinculados a la docencia e investigación en universidades y museos, y sus diversos grados de participación en proyectos expositivos y publicaciones renovadoras permite destacar la pluralidad de enfoques posibles, así como su carácter necesariamente parcial y subjetivo, que no se trata de cubrir con una capa de falsa objetividad positivista, sino que se asume desde el rigor científico, el sentido de la responsabilidad y la honestidad profesional.

Los autores de este libro reflexionan sobre el presente de su propia práctica, analizando la manera y las circunstancias en las que se desarrollaron las construcciones narrativas de la disciplina de las que todos somos deudores, con un gran respeto y sensibilidad hacia las figuras concretas que las protagonizaron. En ese sentido, una de las grandes virtudes de este libro, desde mi punto de vista, es su ecuanimidad en la valoración de los historiadores y sus aportaciones. Los autores muestran una enorme consideración por quienes pusieron los cimientos de la disciplina pues, aunque frecuentemente parezca lo contrario, un profundo revisionismo crítico y la exposición de problemas y limitaciones, no están reñidos con el reconocimiento a la labor de los maestros, y en este caso la reivindicación de la figura de Tormo es patente. Este reconocimiento, además, se extiende independientemente de su posición ideológica o política, especialmente patente al abordar la construcción de la disciplina durante el periodo franquista. Así, se propone la recuperación biográfica de historiadores tan diversos como Moreno Villa, Lafuente Ferrari o Sánchez Cantón, por nombrar tres casos frecuentemente citados. Varios de los escritos de estos autores, que dan pie a la reflexión crítica, se encuentran incluidos en un CD de lecturas complementarias que acompaña al volumen.

El libro se estructura en tres grandes epígrafes, desiguales en número de ensayos y sobre todo en volumen de páginas, titulados «Fundamentos», "Más allá de las Bellas Artes y de Occidente» y «Discursos, contextos y escenarios». En el primero se abordan cuestiones relacionadas con las bases de la narración disciplinar. Se inicia con el extenso ensayo introductorio de Jesusa Vega, que realiza una com- pleta revisión crítica de las principales problemáticas del devenir de la historia del arte en España, atenta al proceso de creación del discurso y su imbricación en el contexto político y social, al proceso de profesionalización e institucionalización, a las luces y las sombras de este desarrollo, a sus principales actores, y a las cuestiones metodológicas. Su texto adelanta muchos de los argumentos que se volverán a plantear en los textos sucesivos y resulta una acertada síntesis de los principales desafíos a los que se ha enfrentado y continúa enfrentándose la disciplina.

El primer epígrafe se completa con dos textos de Javier Portús y Juan Carlos Ruiz Souza, sobre la construcción de los conceptos «escuela española» en la pintura, y «arte mudéjar», respectivamente. Ambos destacan la importancia de variables más allá de lo histórico-artístico (morales, políticas, económicas o nacionalistas), en la construcción de determinados metarrelatos, forjados en relación a los paradigmas artísticos de su época e íntimamente ligados a los procesos de visibilización de las obras. El desarrollo de estos conceptos plantea, además, para ambos autores la posibilidad de explorar los procesos de formación y cambio de los paradigmas de la historia del arte en España, creados en gran medida como respuesta a lo que estaba sucediendo más allá de nuestras fronteras.

El segundo epígrafe trata, en contraposición, de la introducción de otras temáticas de estudio que escapan de la construcción reduccionista de las Bellas Artes que se fraguó en los siglos XVIII y XIX. Por su propio carácter, bajo este epígrafe aparecen los ensayos que conscientemente ponen un mayor foco de atención sobre las nuevas metodologías y el diálogo interdisciplinar. Carmen Bernárdez aborda el problema de la materialidad en el arte, partiendo del arte contemporáneo como caso de estudio, pero sin reducirlo únicamente a este. Plantea el desarrollo de los estudios sobre materialidad y la nueva disciplina de «tecnología del arte» como un campo aún por explorar, que permite problematizar la aproximación formalista y la construcción del corpus de estudio en base a la experiencia estética, objetivo que comparte con la mayor parte de los autores de este libro. Isabel Cervera analiza la evolución de los estudios sobre arte asiático, comenzando por la problemática que entrañan sus distintas nomenclaturas (arte del Extremo Oriente, arte en Asia, etc.). Aborda varias cuestiones que se repiten a lo largo de todo el libro: el desarrollo de la catalogación, la formación 
de un corpus y los procesos de patrimonialización, en una primera fase de desarrollo de la disciplina, y el crecimiento de la atención hacia las prácticas contemporáneas, en función de la visibilización y las presiones del mercado del arte en los últimos años. Ambos ensayos, además, son especialmente críticos con la ausencia de traducciones y el difícil acceso a fuentes primarias y secundarias en España. Cierra este bloque el trabajo de María Rosón sobre la fotografía y su proceso de incorporación a la narración de la historia del arte. Destaca el problema del modelo restrictivo del discurso estético, frente a la apertura que suponen los conceptos de cultura visual y cultura material, y vuelve a plantear el problema del canon, de la aproximación formalista a la historia del arte y sus consecuencias en los procesos de generación de archivo, que vertebran los ensayos de estos primeros dos epígrafes. Su trabajo presenta, además, grandes afinidades con el de Carmen Bernárdez, al subrayar la importancia de la materialidad en el estudio de las fotografías desde su objetualidad física, generadora de prácticas sociales y culturales.

El último epígrafe, «Discursos, contextos, escenarios», se centra en las construcciones narrativas sobre el arte de los siglos XVIII-XX y los cambiantes procesos políticos que contribuyeron a su olvido, su recuperación sesgada o a la construcción de relatos alternativos. Álvaro Molina se ocupa del arte del siglo XVIII, tradicionalmente denostado como un siglo de crisis. La construcción historiográfica de la excepcionalidad de Goya en este contexto remite al ensayo de Portús y lo complementa. Además, en diálogo con el resto de los capítulos, plantea críticamente cómo las aproximaciones formalistas y nacionalistas han dificultado la comprensión de este siglo, cómo la revalorización de esta producción artística al calor de la idoneidad política no implicó un revisionismo historiográfico y cómo las nuevas metodologías pueden abrir nuevos caminos de investigación en el futuro. Es un proceso hasta cierto punto paralelo al que sigue Isabel Tejada al analizar el olvido institucional y posterior recuperación de la pintura del siglo XIX, en este caso durante la primera década del siglo XXI por parte del Museo del Prado, partiendo de las iniciativas previas del Museo d'Orsay. La autora vuelve a plantear el problema de la aproximación formalista y nacionalista, que termina condicionando lo que se hace visible y lo que queda en los márgenes del discurso, como son otras alternativas estéticas y artísticas e incluso otras geografías, destacando la desaparición de cualquier referencia a lo colonial.

Noemí de Haro presenta el único ensayo en el que se desarrolla una de las propuestas de los capítulos introductorios: la recuperación biográfica de las principales figuras de la disciplina. En este caso analiza el trabajo de José María Moreno Galván y Valeriano Bozal, incardinándolos en las complejas circunstancias políticas e intelectuales del franquismo y la transición. La autora pone de manifiesto el compromiso ideológico y social en la práctica de la historia del arte, a través de la problematización de la historiografía y la adopción de nuevas metodologías por parte de estos autores. La apertura de nuevas vías para la historia del arte, en diálogo con el presente y la realidad social enlazan con las preocupaciones manifestadas por los diversos autores de este libro, en particular por Jesusa Vega y por Iñaki Estella, que firma el último capítulo del libro. En él hace un repaso de los primeros años del proyecto Desacuerdos, del que él mismo fue partícipe. Aborda el ejercicio de la disciplina entre la universidad y el museo, en un proyecto renovador que pretendió crear un contramodelo al canon impuesto sobre el arte actual, y que permite profundizar en las similitudes y las distancias en la historia del arte en estas dos instituciones.

Esta publicación de obligada lectura, y relectura, viene a poner sobre la mesa algunos de los problemas fundamentales de la disciplina, y propone una revisión historiográfica bastante completa, aunque se echa en falta la inclusión de algún ensayo dedicado al arte en América. Tanto por su problemática actual como por sus sucesivos giros epistemológicos hubiera sido un necesario complemento a la visión general de este libro y se hubiera establecido como un interesante interlocutor en lo relativo a la construcción historiográfica nacionalista, la reivindicación de la labor profesional de diversos especialistas (Moreno Villa y Angulo son citados frecuentemente), o el papel de las editoriales en la evolución de la disciplina durante buena parte del siglo XX.

Elena Paulino Montero

Kunsthistorisches Institut de Florencia 